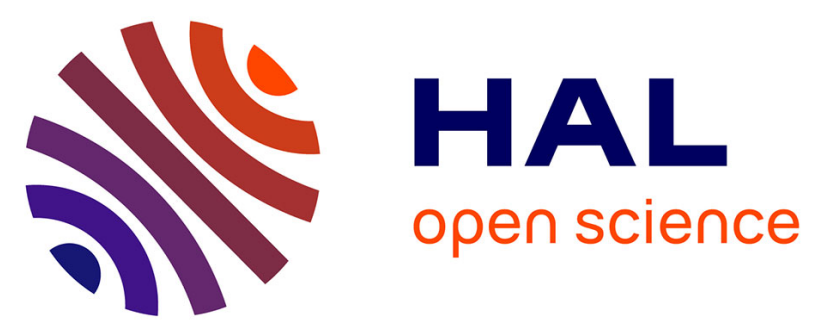

\title{
Bioinspired Oxidative Cyclization of the Geissoschizine Skeleton for Enantioselective Total Synthesis of Mavacuran Alkaloids
}

Maxime Jarret, Victor Turpin, Aurélien Tap, Jean-François Gallard, Cyrille Kouklovsky, Erwan Poupon, Guillaume Vincent, Laurent Evanno

\section{To cite this version:}

Maxime Jarret, Victor Turpin, Aurélien Tap, Jean-François Gallard, Cyrille Kouklovsky, et al.. Bioinspired Oxidative Cyclization of the Geissoschizine Skeleton for Enantioselective Total Synthesis of Mavacuran Alkaloids. Angewandte Chemie International Edition, 2019, 58 (29), pp.9861-9865. 10.1002/anie.201905227 . hal-02322586

\section{HAL Id: hal-02322586 https://hal.science/hal-02322586}

Submitted on 20 Nov 2020

HAL is a multi-disciplinary open access archive for the deposit and dissemination of scientific research documents, whether they are published or not. The documents may come from teaching and research institutions in France or abroad, or from public or private research centers.
L'archive ouverte pluridisciplinaire HAL, est destinée au dépôt et à la diffusion de documents scientifiques de niveau recherche, publiés ou non, émanant des établissements d'enseignement et de recherche français ou étrangers, des laboratoires publics ou privés. 


\title{
Bioinspired Oxidative Cyclization of the Geissoschizine Skeleton for the Enantioselective Total Synthesis of Mavacuran Alkaloids
}

\author{
Maxime Jarret, ${ }^{[a]}$ Victor Turpin, ${ }^{[b]}$ Aurélien Tap, ${ }^{[a]}$ Jean-François Gallard, ${ }^{[c]}$ Cyrille Kouklovsky, ${ }^{[a]}$ Erwan \\ Poupon, ${ }^{*[b]}$ Guillaume Vincent, ${ }^{*[a]}$ and Laurent Evanno*[b]
}

\begin{abstract}
We report the enantioselective total syntheses of mavacurans alkaloids, (+)-taberdivarine $\mathrm{H}, \quad(+)$-16-hydoxymethylpleiocarpamine, (+)-16-epi-pleiocarpamine, and their postulated biosynthetic precursor 16 -formyl-pleiocarpamine. This family of monoterpene indole alkaloids is a target of choice since some of its members are subunits of intricate bisindole alkaloids such as bipleiophylline. Inspired by the biosynthetic hypothesis, we explored an oxidative coupling approach from the geissoschizine framework to form the N1-C16 bond. Quaternization of the aliphatic nitrogen was key to achieve the oxidative coupling induced by $\mathrm{KHMDS} / \mathrm{I}_{2}$ since it hides the nucleophilicity of the aliphatic nitrogen and locks the required cis conformation.
\end{abstract}

Geissochizine (1) is considered as a common biosynthetic precursor of several frameworks (akuammilan, mavacuran, strychnan) encountered in the family of monoterpene indole alkaloids. ${ }^{[1]}$ Despite the recent identification of some enzyme systems, ${ }^{[2]}$ most of the interconnections and mechanisms from geissoschizine (1) remain partially understood and proven (Scheme 1). According to the different hypotheses, divergent oxidative couplings between the $\mathrm{C} 16$ carbon and the $\mathrm{N} 1$ nitrogen, the N4 nitrogen or the C7 carbon would lead respectively to excelsinidines, mavacurans and akuammilans. ${ }^{[3]}$ Mavacurans ${ }^{[4]}$ sparked our interest since its emblematic representative, pleiocarpamine (2) is a subunit encountered in several indole and bisindole alkaloids of particularly complex structure..$^{[5-6]} \mathrm{We}$ already accomplished the synthesis of bipleophylline (8) via oxidative couplings between pyrocatechic acid and pleiocarpamine isolated from plant material. ${ }^{[7]}$ Motivated by the complexity of these frameworks, we sought to develop a synthesis of pleiocarpamine (2) as a benchmark to the total synthesis of other multimeric bisindoles.

Akuammilans ${ }^{[8]}$ strychnans ${ }^{[9]}$ and mavacurans ${ }^{[10]}$ have been the subject of very intense synthetic efforts but, a late stage bioinspired oxidative cyclisation of a geissoschizine type structure was performed only in few occasions. ${ }^{[11-13]}$ In a seminal study,

[a] Maxime Jarret, Dr. Aurélien Tap, Prof. Cyrille Kouklovsky, Dr. Guillaume Vincent

Institut de Chimie Moléculaire et des Matériaux d'Orsay (ICMMO), Equipe MSMT

Univ. Paris Sud, CNRS, Université Paris-Saclay

15, rue Georges Clémenceau, 91405 Orsay, Cedex, France

E-mail: guillaume.vincent@u-psud.fr

[b] Victor Turpin, Prof. Erwan Poupon, Dr. Laurent Evanno

Pharmacognosie et chimie des substances naturelles, BioCIS Univ. Paris-Sud, Université Paris-Saclay, CNRS

92290 Châtenay-Malabry, France E-mail: laurent.evanno@upsud.fr, erwan.poupon@u-psud.fr

[c] Jean-François Gallard, ICSN, Institut de Chimie des Substances Naturelles, CNRS UPR 2301, Université Paris-Saclay, 1 avenue de la Terrasse, 91198 Gif-sur-Yvette Cedex, France

Supporting information for this article is given via a link at the end of the document
Martin reported the direct cyclization of 16-deformylgeissoschizine leading directly to akuammicine (9). ${ }^{[12]}$ An oxidative chlorination in the presence of $\mathrm{SnCl}_{4}$ gave a chloroindolenine that underwent skeletal reorganization in basic conditions. A transient formation of an akuammilan structure was postulated, and similar correlation between the akuammilans and the stychnans was evidenced by us in buffered conditions. ${ }^{[14]}$ To date, for the synthesis of akuammilans, C7-C16 oxidative couplings were only performed on simplified structures. ${ }^{[15]}$

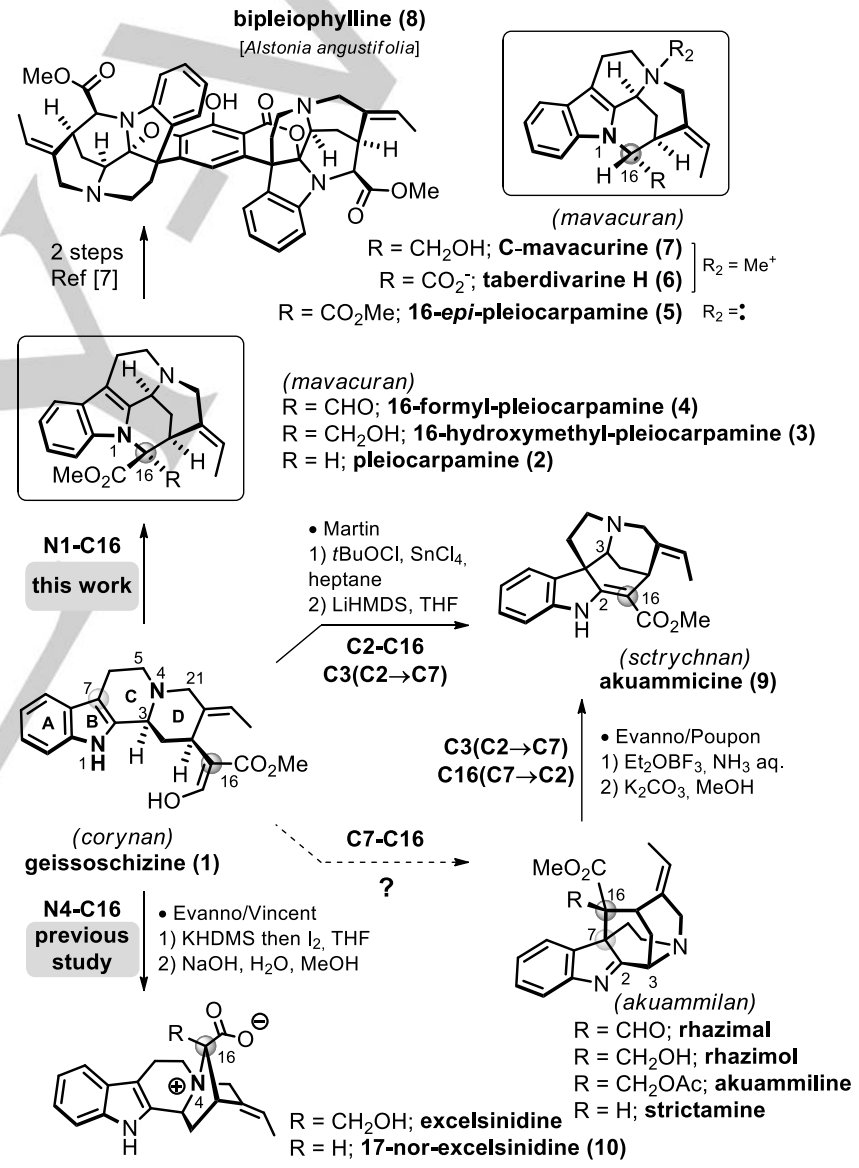

Scheme 1. Postulated biosynthesis and bioinspired synthetic approaches of the mavacurans, akuammilans, strychnans and excelsinidines.

Toward mavacurans synthetic approaches are even more limited. ${ }^{[10]}$ Notably, Sakai ${ }^{[10 b, c]}$ and then Harley-Mason ${ }^{[10 \mathrm{~d}]}$ used a sequence of oxidative chlorination of the $\mathrm{C} 16$ carbon, followed by a nucleophilic substitution by $\mathrm{N} 1$ nitrogen performed on a substrate lacking the CD-ring junction in order to benefit from more flexibility. During the preparation of the present manuscript, Takayama reported a racemic synthesis of mavacuran alkaloids using a metal carbenoid cyclization of a 16-deformyl- 
geissoschizine-type structure bearing a carbenoid at C16. ${ }^{[16]}$ The key cyclization delivered $( \pm)$-16-epi-pleiocarpamine $(5)$ as the major product and ( \pm )-pleiocarpamine (2) as a minor product. In a previous communication, we reported a N4-C16 biomimetic oxidative cyclization of geissoschizine (1) induced by $\mathrm{KHMDS} / \mathrm{I}_{2}$ leading to zwitterionic 17-nor-excelsinidine (10). ${ }^{[13]}$ We present herein further developments to control the N1-C16 bond formation and the application to the enantioselective total synthesis of mavacuran alkaloids: 16-hydroxymethyl-pleiocarpamine (3), 16epi-pleiocarpamine (5) and taberdivarine $H(6)$ as well as 16formyl-pleiocarpamine (4), a postulated biosynthetic intermediate yet to be isolated from natural sources.

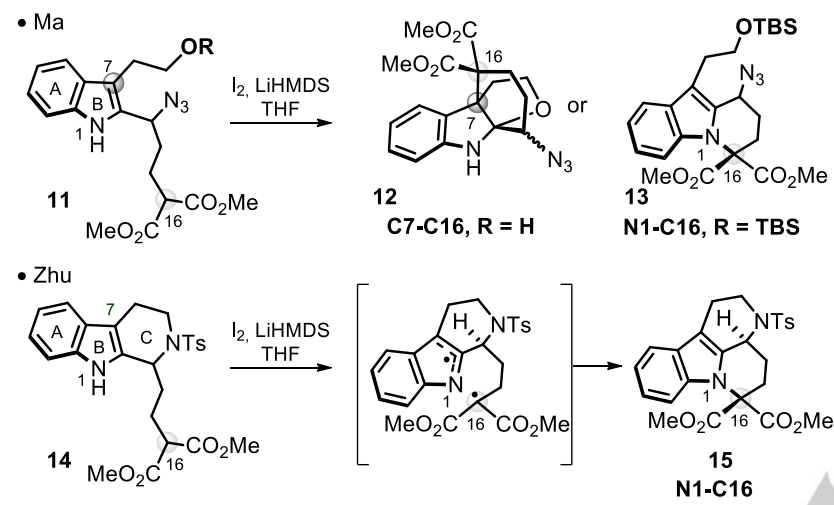

geissoschizine (1) led to the excelsinidines core (compound 10). [13] Exclusive formation of the framework of $\mathbf{1 0}$ might be rationalized by the NMR conformational study of geissoschizine (1) ${ }^{\left[{ }^{[3]}\right]}$ In solution, the molecule adopts a C3-N4 trans configuration favorable to the formation of the excelsinidines core. As demonstrated by Eckermann and Gaich, a C3-N4 cis configuration is required to insure proximity between $\mathrm{C} 16$ carbon and the indole nucleus and can be locked by benzylation (Scheme 2). ${ }^{[3 g, 18]}$ With all those considerations, we adopted a strategy consisting in the alkylation of the aliphatic nitrogen to inhibit its reactivity and favor the cis geissoschizine (1) configuration and then to use the $\mathrm{KHMDS} / \mathrm{I}_{2}$ oxidative conditions for the $\mathrm{N} 1-\mathrm{C} 16$ bond formation.

We accessed (+)-geissoschizine and its derivatives according to our recent synthesis which was inspired by the works of Martin and Cook (Scheme 3) $)^{[13]}$ The diastereoselective Martin's vinylogous Mannich addition of a silyl ketene acetal onto $\beta$-dihydrocarboline 19 derived from (D)-tryptophan ${ }^{[19]}$ was followed by $\mathrm{N}$-allylation of the secondary amine with an ally bromide. According to Cook, formation of the D-ring was promoted by $\mathrm{Ni}(\mathrm{COD})_{2}$-mediated intramolecular addition of the vinyl iodide onto the unsaturated ester of $(+)-20$ for which the diastereoselectivity was directed by the benzyl ester. ${ }^{[20]}$ Removal of the latter was effected in 3 steps leading to $(+)$-16-deformylgeissoschizine (22) and to (+)-geissoschizine (1) after a known formylation step. In addition, dimethyl malonate $(-)-23$ was also obtained in $86 \%$ yield from (+)-22.

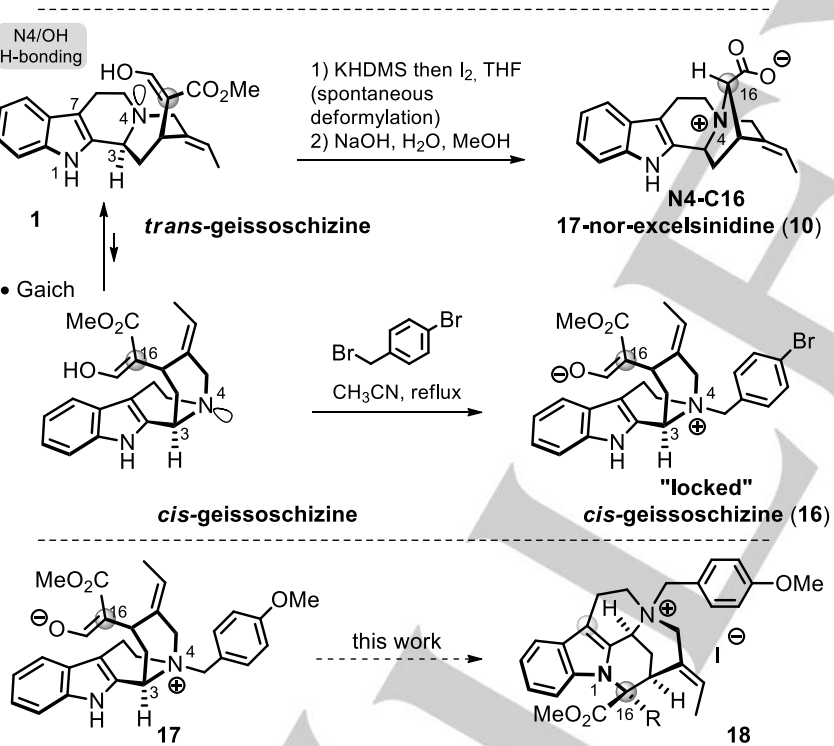

Scheme 2. Divergent oxidative couplings for the formation of the N1-C16 or C7C16 bonds and conformational studies of geissoschizine. 16-17 zwitterions

In the context of alkaloids total syntheses, Ma and Zhu constructed, at early stages, either the $\mathrm{C} 7-\mathrm{C} 16$ bond $^{[15 a, b]}$ or the $\mathrm{N} 1-\mathrm{C} 16$ bond ${ }^{[15 b, 17]}$ bond using LiHMDS// 2 oxidative conditions (Scheme 2). First, LiHMDS deprotonates both a malonate and the $\mathrm{NH}$ of an indole $(11,14)$ followed by an oxidation of the resulting dianion with $\mathrm{I}_{2}$. Ma and Zhu results suggested the applicability of the oxidative coupling to the synthesis of mavacurans but, in our hands, slightly modified conditions $\left(\mathrm{KHMDS} / \mathrm{I}_{2}\right)$ applied to
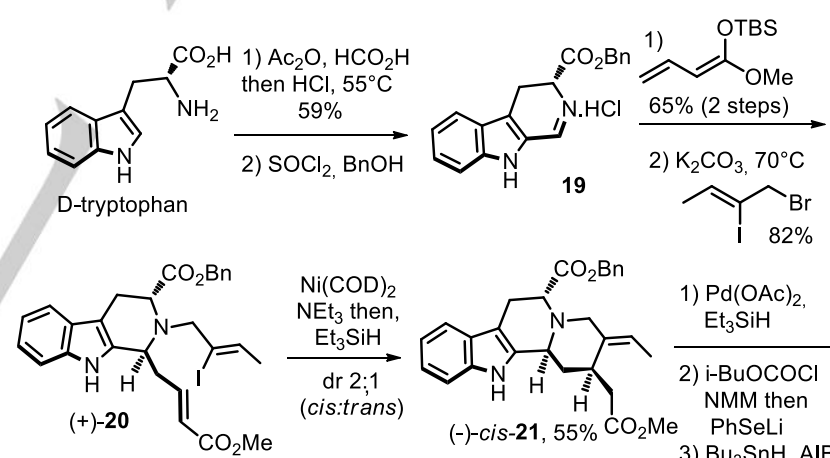

1) $\mathrm{Pd}(\mathrm{OAc})_{2}$ $\mathrm{Et}_{3} \mathrm{SiH}$

2) i-BuOCOCl $\mathrm{PhSeLi}$

3) $\mathrm{Bu}_{3} \mathrm{SnH}, \mathrm{AIBN}$ (53\%, 3 steps)
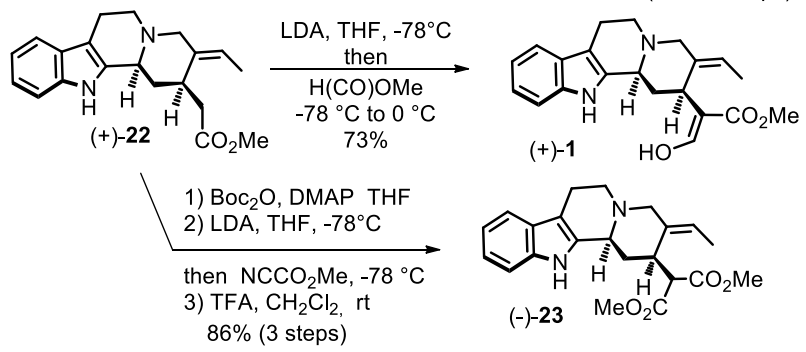

Scheme 3. Synthesis of 16-deformyl-geissoschizine (22), geissoschizine (1) and geissoschizine malonate $\mathbf{2 3}$ according to our previous work.

With a straightforward access to the geissoschizine framework, we were in position to evaluate our hypothesis of oxidative cyclization after quaternization of the aliphatic nitrogen N4. As 
demonstrated by Ma and then Zhu or us, the presence of a dicarbonyl functionality at C16 is essential to effect related oxidative couplings and geissoschizine itself seems to be a suitable candidate. Heating geissoschizine (1) with p-methoxybenzylbromide in acetonitrile led, as expected, to ammonium (-)-17. Deprotonation of the indolyl $\mathrm{NH}$ of $\mathbf{1 7}$ with KHMDS was followed by addition of $I_{2}$. For the first time, we observed the formation of the desired mavacuran skeleton via the long-expected formation of the $\mathrm{N} 1-\mathrm{C} 16$ bond as a mixture of 25 and deformyl counterpart 26. This reaction reveals to be stereoselective but, careful NOESY analysis showed that the $\mathrm{C} 16$ stereochemistry for both compounds $\mathbf{2 5}$ and $\mathbf{2 6}$ corresponds to a 16-epi-pleiocarpamine-type stereochemistry rather than the pleiocarpamine one. We then reasoned that the use of a symmetric dicarbonyl at $\mathrm{C} 16$ (compound 24 ) would allow us to fix the stereochemistry at $\mathrm{C} 16$ at a later stage and would also circumvent the problem of uncontrolled deformylation of 25 . Thus, the same sequence of quaternization of $\mathrm{N} 4$ and subsequent $\mathrm{N} 1$ C16 oxidative coupling applied to dimethyl malonate-containing 24 proceeded in $76 \%$ yield over 2 steps (compound (+)-28).
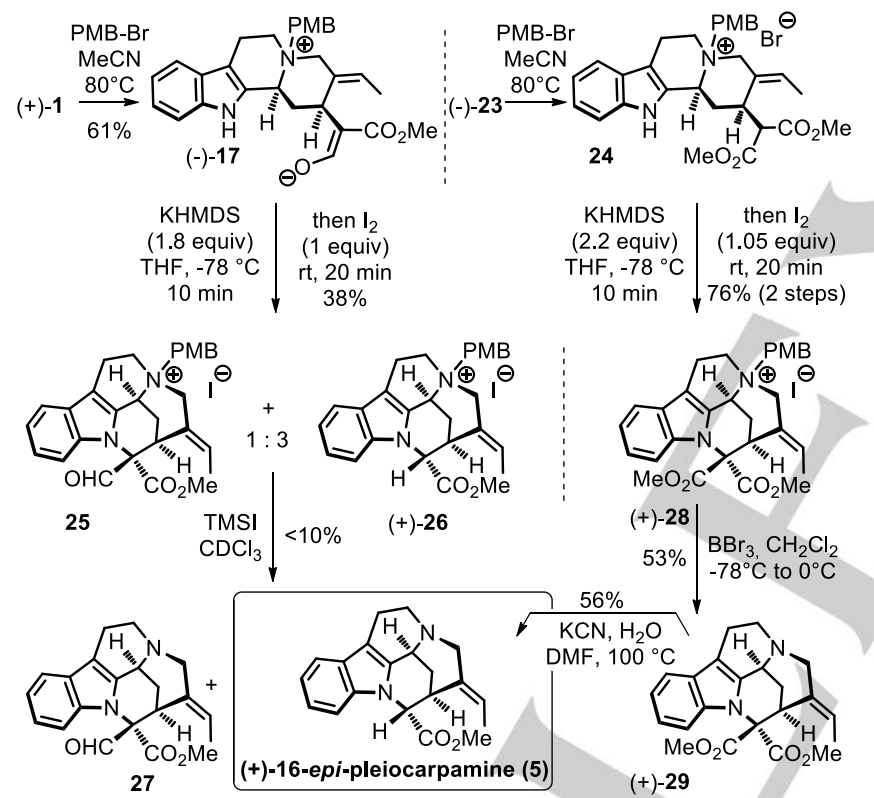
$\checkmark$

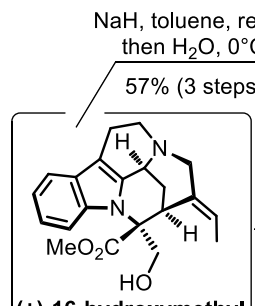

(+)-16-hydroxymethyl pleiocarpamine (3)
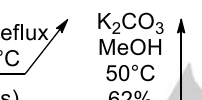

$(+)-29$
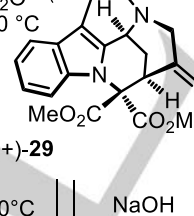

(2 steps)

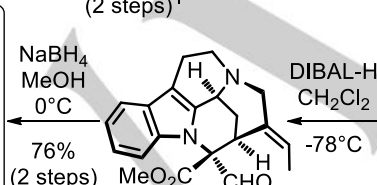

(2 steps) $\mathrm{MeO}_{2} \mathrm{C} " \mathrm{CHO}$

4

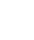

Scheme 4. Total synthesis of 16-epi-pleiocarpamine and 16-hydroxymethyl pleiocarpamine via N1-C16 oxidative cyclization from N4-PMBgeissoschizinium derivatives. the PMB was necessary to restore the tertiary amine at $\mathrm{C} 4$. It was at first effected with TMS iodide on the mixture of $\mathbf{2 5}$ and deformyl 26 which delivered (with a poor yield but enough to identify) a mixture of 16-epi-pleiocarpamine (5) and 16-epi-16-formylpleiocarpamine (27). It then turned to be more convenient to operate from malonate (+)-28. Indeed, deprotection of N4 was achieved with $\mathrm{BBr}_{3}$ to give (+)-29 in $53 \%$ yield. Subsequently, Krapcho decarboxylation with KCN delivered efficiently (+)-16epi-pleiocarpamine (5).

In order to desymmetrize the diester at $\mathrm{C} 16$ of $(+)-29$, addition of DIBALH reduced selectively the more accessible ester into an aldehyde to yield 16-formyl-pleiocarpamine (4) which is believed to be the biosynthetic precursor of pleiocarpamine (2) as the direct product of oxidative cyclization of geissoschizine (1). The reaction delivered $\mathbf{4}$ with a complete control of $\mathrm{C} 16$ stereocenter and, at this stage, the configuration of the remaining ester was matching with pleiocarpamine (2). Deformylation by heating 4 in methanol under basic conditions delivered (+)-16-epi-pleiocarpamine (5). Further reduction of aldehyde 4 with $\mathrm{NaBH}_{4}$ delivered (+)-16hydroxymethyl-pleiocarpamine (3), the next biosynthetic intermediate en route to pleiocarpamine. The heating of $\mathbf{3}$ with $\mathrm{NaH}$ induced the release of formaldehyde to give again (+)-16epi-pleiocarpamine (5) after an aqueous quench at $0^{\circ} \mathrm{C} .{ }^{[21]}$ The desymmetrisation of malonate (+)-29 was also possible via the selective saponification of the most accessible ester. Heating of the resulting carboxylic acid $\mathbf{3 0}$ resulted in a decarboxylation to, once again, form (+)-16-epi-pleiocarpamine (5). In all these attempts, the selective formation of (+)-16-epi-pleiocarpamine (5) over pleiocarpamine (2) is observed even though we started from substrates bearing the proper $\mathrm{C} 16$ pleiocarpamine-type stereochemistry (compounds $\mathbf{3}, \mathbf{4}$ and $\mathbf{3 0}$ ). It could be explained as in all cases an enolate or enol is formed at C16 which is converted to the more thermodynamically stable epimer $\mathbf{5}$.

Indeed, performing the N1-C16 oxidative coupling on a substrate containing an ammonium at N4 seemed to be perfectly adapted to the total synthesis of (+)-taberdivarine $\mathrm{H}$ which contains an N4methyl ammonium, like C-mavacurine (7). Malonate (-)-23 was $\mathrm{N}$-methylated with methyl iodide. Resulting ammonium $\mathbf{3 1}$ was then subjected to the preceding oxidative coupling conditions to form the N1-C16 bond of (+)-32 in 75\% yield over 2 steps. Finally, a double saponification accompanied by a decarboxylation furnished (+)-taberdivarine $\mathrm{H}(6)$ in $58 \%$ yield.

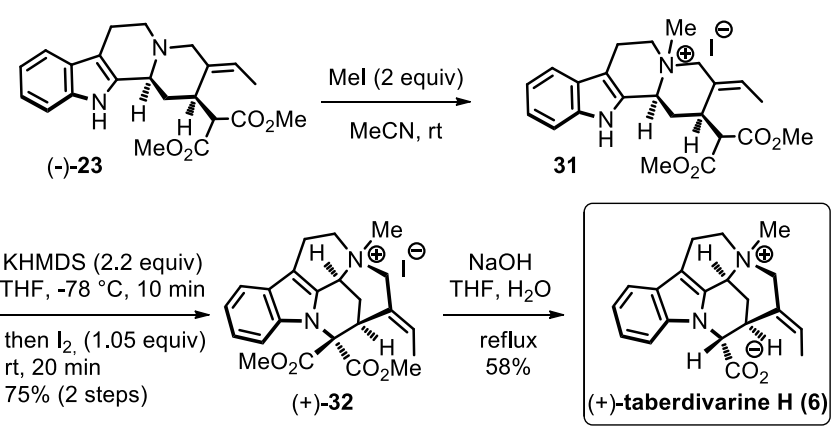

Scheme 5. Total synthesis of taberdivarine $\mathrm{H}$. 
In conclusion, we found a solution to the long-standing problem of the oxidative cyclization of the geissoschizine skeleton to forge the mavacuran scaffold via the formation of the key N1-C16 bond. The quaternization of the N4-quinolizidine nitrogen was decisive to achieve this endeavor. The formation of an N4 ammonium efficiently sequesters the superior nucleophilicity of $\mathrm{N} 4$ in comparison to the $\mathrm{N} 1$ indolic nitrogen and, moreover, favors the cis conformation of the geissoschizine framework which brings closer the indole nucleus and the C16 malonate. This strategy allowed us to achieve the total synthesis of (+)-16-epipleiocarpamine, (+)-16-hydroxymethyl-pleiocarpamine and (+)taberdivarine $\mathrm{H}$ as well as 16 -formyl-pleiocarpamine, a postulated biosynthetic intermediate.

\section{Experimental Section}

Experimental Details

\section{Acknowledgements}

We gratefully acknowledge the ANR (ANR-15-CE29-0001; "Mount Indole"), the Université Paris-Sud and the CNRS for financial support. We thank Aurélien Alix for helpful discussions and Jean-Pierre Baltaze for NMR assistance.

Keywords: monoterpene indole alkaloids • oxidative coupling • mavacuran $\cdot$ biosynthesis $\cdot$ pleiocarpamine

[1] Reviews on monoterpene indole alkaloids: a) R. B. Herbert, in Chem. Heterocycl. Compd. (Ed.: J.E. Saxton), John Wiley \& Sons, Inc., 1983, pp. 1-46; b) S. E. O'Connor, J. J. Maresh, Nat. Prod. Rep. 2006, 23 532-547; c) L. F. Szabó, Molecules 2008, 13, 1875-1896

[2] a) E. C. Tatsis, I. Carqueijeiro, T. Dugé de Bernonville, J. Franke, T.-T. T. Dang, A. Oudin, A. Lanoue, F. Lafontaine, A. K. Stavrinides, M. Clastre V. Courdavault, S. E. O'Connor, Nat. Commun. 2017, 8, 316; b) Y. Qu, M. E. A. M. Easson, R. Simionescu, J. Hajicek, A. M. K. Thamm, V. Salim, V. De Luca, Proc. Natl. Acad. Sci. U S A. 2018, 115, 3180-3185.

[3] a) E. Wenkert, B. Wickberg, J. Am. Chem. Soc. 1965, 87, 1580-1589; b) A. I. Scott, Acc. Chem. Res. 1970, 3, 151-157; c) M. Pinar, M. Hanaoka M. Hesse, H. Schmid, Helv. Chim. Acta, 1971, 54, 15-43; d) G. Hugel, D. Royer, L. Le Men-Olivier, B. Richard, M.-J. Jacquier, J. Lévy, J. Org Chem. 1997, 62, 578-583; e) L. Zhang, C.-J. Zhang, D.-B. Zhang, J. Wen, X.-W. Zhao, Y. Li, K. Gao, Tetrahedron Lett. 2014, 55, 1815-1817; f) H. Takayama, T. Watanabe, H. Seki, N. Aimi, S. Sakai, Tetrahedron Lett. 1992, 45, 6831-6834; g) R. Eckermann, T. Gaich, Chem. - Eur. J. 2016, 22, 5749-5755.

[4] Structure of C-Mavacurine, pleiocarpamine and 16-epi-pleiocapamine: M. Hesse, W. V. Philipsborn, D. Schumann, G. Spiteller, M. SpitellerFriedmann, W. I. Taylor, H. Schmid, P. Karrer, Helv. Chim. Acta 1964 47, 878-911; isolation of 16-epi-pleiocapamine: b) N. Langlois, L. Diatta, R. Z. Andriamialisoa, Phytochemistry 1979, 18, 467-471; isolation of 16hydroxymethyl-pleiocarpamine: c) C. Kan, J.-R. Deverre, T. Sevenet, J.C. Quirion, H.-P. Husson, Nat. Prod. Lett. 1995, 7, 275-281; isolation of taberdivarine H: d) B.-J. Zhang, X.-F. Teng, M.-F. Bao, X.-H. Zhong, L. Ni, X.-H. Cai, Phytochemistry 2015, 120, 46-52.

[5] Isolation of bipleiophylline: a) T.-S. Kam, S.-J. Tan, S.-W Ng, K. Komiyama, Org. Lett. 2008, 10, 3749-3752; pycnanthinine: b) A. A. Gorman; H. Schmid, Monatsh. Chem. 1967, 98, 1554-1566; goniomedine A: c) M. A. Beniddir, M.-T. Martin, M.-E. Tran Huu Dau, P.
Grellier, P. Rasoanaivo, F. Guéritte, M. Litaudon, Org. Lett. 2012, 14 4162-4165; contortarine A: d) J. T. Ndongo, J. N. Mbing, M. F. Tala, A. Monteillier, D. E. Pegnyemb, M. Cuendet, H. Laatsch, Phytochemistry 2017, 144, 189 -196; pleiocraline: e) B. C. Das, J.-P. Cosson, G. Lukacs J. Org. Chem. 1977, 42, 2785-2786; f) pleiocorine: B. C. Das, J. P. Cosson, G. Lukacs, P. Potier, Tetrahedron Lett. 1974, 15, 4302; g) plumocraline: M. J. Jacquier, J. Vercauteren, G. Massiot, L. Le Men-Olivier, J. Pusset, T. Sevenet, Phytochemistry, 1982, 21, 29732977; macrocarpamine: h) F. Mayerl, M. Hesse, Helv. Chim. Acta 1978 61, 337-351; 19-epi-pleiomutinine A: i) C. Lavaud, G. Massiot, J. Vercauteren, L. Le Men-Olivier, Phytochemistry, 1982, 21, 445 - 447; i) pleiomaltinine: j) S.-J. Tan, Y.-M. Choo, N. F. Thomas, W. T. Robinson, K. Komiyama, T.-S. Kam, Tetrahedron, 2010, 66, 7799-7806; k) Y. Hirasawa, H. Arai, A. Rahman, I. Kusumawati, N. C. Zaini, O. Shirota, H. Morita, Tetrahedron, 2013, 69, 10869 - 10875.

[6] Hemisyntheses of macrocarpamine: a) T. Gan, J. M. Cook, Tetrahedron Lett. 1996, 37, 5037-5038; villalstonine: b) D. E. Burke, P. W. Le Quesne, J. Chem. Soc. Chem. Commun. 1972, 678-678; c) Y. Bi, J. M. Cook, P. W. Le Quesne, Tetrahedron Lett. 1994, 35, 3877-3878; pleiomaltinine: d) R. E. Ziegler, S.-J. Tan, T.-S. Kam, J. A. Porco Jr, Angew. Chem. Int. Ed. 2012, 51, 9348-9351; Angew. Chem. 2012, 124, 9482 - 9485.

[7] Hemisynthesis of bipleiophylline and voacalgine A with structure revision of the latter: a) D. Lachkar, N. Denizot, G. Bernadat, K. Ahamada, M. A Beniddir, V. Dumontet, J.-F. Gallard, R. Guillot, K. Leblanc, E. Otogo N'nang, V. Turpin, C. Kouklovsky, E. Poupon, L. Evanno, G. Vincent, Nat. Chem. 2017, 9, 793-798; b) N. Denizot, D. Lachkar, C. Kouklovsky, E. Poupon, L. Evanno, G. Vincent, Synthesis 2018, 50, 4229-4242.

[8] For reviews: a) R. Eckermann, T. Gaich, Synthesis 2013, 45, 2813-2823; b) J. M. Smith, J. Moreno, B. W. Boal, N. K. Garg, Angew. Chem. 2015 , 127, 410-422; Angew. Chem. Int. Ed. 2015, 54, 400-412; c) G. L. Adams, A. B. Smith, in Alkaloids Chem. Biol. (Ed.: H.-J. Knölker), Academic Press, 2016, pp. 171-257; d) C. Wang, S. Zhang, Y. Wang, S.-H. Huang, R. Hong, Org. Chem. Front. 2018, 5, 447-452.

[9] For reviews: a) J. Bonjoch, D. Solé, Chem. Rev. 2000, 100, 3455-3482; b) J. S. Cannon, L. E. Overman, Angew. Chem. Int. Ed. 2012, 51, 42884311; Angew. Chem. 2012, 124, 4362-4386.

[10] a) D. D. O'Rell, F. G. H. Lee, V. Boekelheide, J. Am. Chem. Soc. 1972, 94, 3205-3212; b) S.-I. Sakai, N. Shinma, Heterocycles 1976, 4, 985988; c) S.-I. Sakai, N. Shinma, Yakugaku Zasshi, 1978, 98, 950-964; d) M. J. Caverley, B. J. Banks, J. Harley-Mason, Tetrahedron Lett. 1981, 22, 1635-1638; e) M. L. Bennasar, E. Zulaica, J. M. Jimenez, J. Bosch, J. Org. Chem. 1993, 58, 7756-7767.

[11] For a review on oxidative couplings for the total synthesis of indole alkaloids: K. Nagaraju, D. Ma, Chem. Soc. Rev. 2018, 47, 8018-8029.

[12] a) S. F. Martin, C. W. Clark, M. Ito, M. Mortimore, J. Am. Chem. Soc. 1996, 118, 9804-9805; b) M. Ito, C. W. Clark, M. Mortimore, J. B. Goh, S. F. Martin, J. Am. Chem. Soc. 2001, 123, 8003-8010.

[13] M. Jarret, A. Tap, C. Kouklovsky, E. Poupon, L. Evanno, G. Vincent Angew. Chem. Int. Ed. 2018, 57, 12294 - 12298; Angew. Chem. 2018, 130, 12474-2478.

[14] S. Benayad, K. Ahamada, G. Lewin, L. Evanno, E. Poupon, Eur. J. Org Chem. 2016, 2016, 1494-1499.

[15] a) W. Zi, W. Xie, D. Ma, J. Am. Chem. Soc. 2012, 134, 9126-9129; b) M. Teng, W. Zi, D. Ma, Angew. Chem. Int. Ed. 2014, 53, 1814-1817; Angew. Chem. 2014, 126, 1845-1848; c) for an account on the indole-enolate oxidative coupling, see: W. Zi, Z. Zuo, D. Ma, Acc. Chem. Res. 2015, 48, 702-711.

[16] K. Sato, N. Kogure, M. Kitajima, H. Takayama, Org. Lett. 2019, doi: 10.1021/acs.orglett.9b01084.

[17] W. Ren, N. Tappin, Q. Wang, J. Zhu, Synlett 2013, 24, 1941-1944.

[18] In their recent report, Takayama and co-workers formed a $\mathrm{N} 4-\mathrm{BH}_{3}$ complex to lock the cis-conformation, see ref. 16 .

[19] S. F. Martin, C. W. Clark, J. W. Corbett, J. Org. Chem. 1995, 60, 32363242.

[20] S. Yu, O. M. Berner, J. M. Cook, J. Am. Chem. Soc. 2000, 122, 78277828 
[21] This in contrast with the work of Quirion and co-workers who reported that such conditions delivered pleiocarpamine, see ref. $4 \mathrm{c}$. 
Entry for the Table of Contents (Please choose one layout)

Layout 1:

\section{COMMUNICATION}

The long standing problem of the bioinspired oxidative cyclization of geissoschizine to the mavacuran skeleton has been resolved. The key C16-N1 bond could be formed by locking the cis conformation through quaternization of the aliphatic nitrogen which allowed the total syntheses of (+)-taberdivarine $\quad \mathrm{H}, \quad(+)-6$ hydoxymethyl-pleiocrapamine, (+)-16epi-pleiocarpamine, and their postulated biosynthetic precursor 16formylpleiocarpamine.

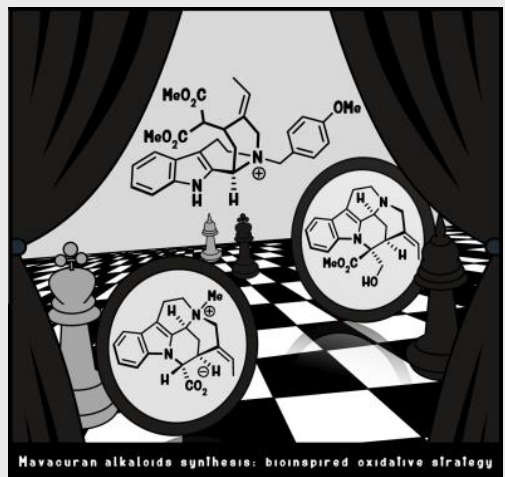

Maxime Jarret, Victor Turpin, Aurélien Tap, Jean-François Gallard, Cyrille Kouklovsky, Erwan Poupon, * Guillaume Vincent, * Laurent Evanno*

Page No. - Page No.

Bioinspired Oxidative Cyclization of the Geissoschizine Skeleton for the Enantioselective Total Synthesis of Mavacuran Alkaloids

Layout 2:

\section{COMMUNICATION}

((Insert TOC Graphic here))
Author(s), Corresponding Author(s)*

Page No. - Page No.

Title 